\title{
Falhas do sistema alimentar brasileiro: contribuiçóes da geografia literária para o fortalecimento da democracia alimentar
}

\section{| ${ }^{1}$ Michelle Cristine Medeiros Jacob, ${ }^{2}$ Viviany Moura Chaves I}

Resumo: A necessidade de reformular sistemas

alimentares é uma constante nos debates das Políticas de Alimentação e Nutrição em todo o mundo. A ciência da Nutrição, nesse cenário, tem a oportunidade de avaliar sua abordagem hegemônica, ligada ao paradigma biológico, visando a um maior engajamento político nas questôes que fragilizam seu sistema alimentar. Buscou-se, com este trabalho, demonstrar como o processo histórico e social de construção do sistema alimentar brasileiro relaciona-se com falhas de segurança alimentar e nutricional atuais. Trata-se de pesquisa qualitativa, que tomou como perspectiva de método a geografia literária. $\mathrm{O}$ território brasileiro foi dividido em sete manchas culinárias, porções do território que constituem regióes para o estudo social da alimentação. Compuseram seu corpus 27 trabalhos literários, de 20 escritores brasileiros, coletados e analisados com o apoio das dimensóes conceituais definidas no estudo: espaços narrativos e objetos culinários. O mau uso da terra, a comoditização da comida e a oferta indiscriminada de alimentos industrializados foram listadas como as principais falhas no sistema alimentar analisado. A abordagem das Ciências Humanas e Sociais pode oferecer importante contribuição à Nutrição para maior protagonismo em problemas do sistema alimentar relacionados com aspectos socioculturais.

\footnotetext{
> Palavras-chave: Segurança Alimentar e Nutricional; desenvolvimento sustentável; Educação Alimentar e Nutricional; fatores sociológicos; pesquisa qualitativa.
}

\author{
' Universidade Federal do Rio \\ Grande do Norte, Departamento \\ de Nutrição. Programa de Pós- \\ Graduação em Ciências Sociais. \\ Natal-RN, Brasil (michellejacob@ \\ ufrn.edu.br). \\ ORCID: 0000-0002-4881-7285 \\ ${ }^{2}$ Universidade Federal do Rio \\ Grande do Norte, Programa \\ de Pós-Graduação em Ciências \\ Sociais. Natal-RN, Brasil \\ (vivianymourachaves@hotmail.com). \\ ORCID: 0000-0002-9654-7152
}

Recebido em: 05/03/2018 Revisado em: 13/09/2018 Aprovado em: 13/12/2018 


\section{Introdução}

O uso social da terra e o fomento a práticas alimentares locais e ao desenvolvimento sustentável - pautado na integridade dos recursos naturais, na resiliência econômica, no bem-estar social e na boa governança - têm sido a tônica dos debates no âmbito das políticas de alimentação e nutrição em todo o mundo (FAO, 2014a; MASON; LANG, 2017).

Os aspectos do sistema produtivo, como a estrutura fundiária concentrada, a sustentabilidade do sistema adotado, o equilíbrio entre a produção de commodities direcionada para o mercado internacional e de alimentos para o consumo interno, têm reflexos importantes nas questóes voltadas para a segurança alimentar e nutricional (SAN) (FAO, 2014b). Perpassam essa discussão os diversos riscos impostos aos trabalhadores rurais, o acesso da população a alimentos seguros, o mau uso da terra, o esgotamento dos recursos naturais via apropriaçáo do capital privado dos sistemas agrícolas globais, os riscos impostos à biodiversidade, à soberania e à SAN das populaçôes em todas as suas dimensôes (WALK FREE FOUNDATION, 2016; ABRASCO, 2015; ROCHA, 2013; FAO, 2012).

A formulação de políticas públicas de alimentação deve considerar o caráter multissetorial de suas ações, aderindo a uma visão sistêmica que considere as inter-relaçôes entre os elementos que compóem o sistema alimentar, como a economia, a cultura, o meio ambiente, a política etc. (MALUF; REIS, 2013). Num estudo desenvolvido por Lawrence e seus colaboradores (2015), foi proposto um esquema que auxiliasse no redesenho de políticas públicas, visando à construção de sistemas alimentares saudáveis e sustentáveis, ou seja, um sistema alimentar que oferece SAN a todos, de modo que as bases econômicas, sociais e ambientais para gerar uma alimentação saudável e adequada não sejam comprometidas (HLTF, 2015). Nesta análise, verificou-se que uma mudança que vise à transformação do sistema depende da promoção da democracia alimentar, um cenário em que os cidadãos têm conhecimento e se envolvem ativamente com as questóes que perpassam o sistema alimentar onde se inserem (LANG, 1999).

A Nutrição, neste contexto, tem a oportunidade de avaliar sua abordagem hegemônica, ligada ao paradigma biológico, visando a um maior engajamento político nas questôes que fragilizam seu sistema alimentar. Por exemplo, pode imprimir avanços em suas práticas de educação alimentar e nutricional (EAN), trazendo-as para um cenário que vai além da orientação nutricional de consumo, 
e que busca o engajamento social e democrático dos cidadãos em todas as fases do sistema alimentar (LANG, 2005). Alguns estudos sobre intervenção no campo da EAN mostraram uma lacuna existente entre a teoria e a prática, indicando a necessidade de desenvolvimento de intervençôes que abordem a alimentação de uma forma sistêmica e com uso de metodologias ativas, sobretudo a partir de contribuiçôes com o campo das Humanidades (RAMOS; SANTOS; REIS, 2013). No Brasil, essa ideia é reforçada pelo Marco de Referência de Educação Alimentar e Nutricional para as Políticas Públicas, que tem como um dos seus nove princípios a necessidade da abordagem do sistema alimentar na sua integralidade (BRASIL, 2012).

A abordagem das Ciências Humanas e Sociais pode oferecer uma importante contribuição à Nutrição nesse cenário. Pensando nisso, é que foi proposto o projeto Atlas Culinário da Literatura Brasileira: Alimentação e Cultura, no ano de 2014, em uma universidade pública do Nordeste brasileiro. A perspectiva de método que guiou o projeto foi a geografia literária, onde o texto literário em si pode ser compreendido como um espaço narrativo, inacabado, produto de inter-relações entre o seu contexto de produção, a voz ficcional e os sentidos do leitor (HONES, 2017). Com a geografia literária, se buscou acessar questôes sociais e históricas presentes em diferentes espaços do território e ligadas à alimentação, facilitando sua leitura por meio da criação de mapas.

Alguns mapas foram desenvolvidos e testados no âmbito de escolas públicas locais e obtiveram avaliação positiva por parte dos estudantes e professores envolvidos, conforme relata Santos (2016). Em síntese, o trabalho focado nas questóes do território e com o apoio de obras da literatura local motivou o discente a refletir, relacionar a sua história e propor discursos de reinvenção, atuando, assim, como metodologia ativa no desenvolvimento de práticas de EAN focadas na promoção da democracia alimentar.

A problematização deste estudo partiu da compreensão de que os processos históricos, políticos e sociais que atuam na determinação da SAN, e que englobam a complexa dinâmica dos aspectos que envolvem o sistema alimentar, têm suas fragilidades refletidas numa longa trajetória de avanços e retrocessos, marcadas pela frágil institucionalidade dos modelos de gestão e produção do país. Logo, aprimorar a compreensão sobre a produçáo social da insegurança alimentar e nutricional e ampliar as possibilidades de realizar açóes de EAN pautada em uma vertente crítica, visando ao fortalecimento da democracia alimentar, são elucidaçóes teóricas que deram suporte ao objetivo deste estudo. 
Ao pensar na relação do contexto histórico, político e social de construção do sistema alimentar brasileiro, seu papel na produção de falhas de SAN e a consequente dificuldade encontrada nos esforços de problematização, a exemplo da EAN, cabe incitar a algumas perguntas: como essas obras de literatura nos apoiam em uma anáise social da questão alimentar relacionada com a Nutrição? Que falhas podem ser apontadas a partir do nosso corpus? Que fatores históricos e sociais atuam na sua construção?

Com esse fim, o presente artigo objetivou demonstrar como o processo histórico e social de construção do sistema alimentar brasileiro relaciona-se com falhas de SAN atuais. Estas falhas foram captadas por meio da leitura de mapas produzidos no âmbito da pesquisa com o suporte de método da geografia literária.

\section{Métodos}

\section{Bases teóricas}

No país, a ideia de produzir mapas com o fim de realizar uma leitura sociocultural do fenômeno alimentar nasceu com Josué de Castro. Em Geografia da fome, ele mapeou as carências nutricionais no território brasileiro e afirmou a eficácia da ciência da Geografia na tarefa de localizar e correlacionar os fenômenos naturais e sociais como a fome, expondo assim sua natureza política (CASTRO, 2006).

A utilização da literatura como referência para produçáo de cartografias oferece a possibilidade de uma abordagem transdisciplinar, própria do texto literário (BARTHES, 2007). Franco Moretti, que empreendeu uma pesquisa de compreensão de fenômenos descritos nas obras literárias do século XIX, afirma que o apoio de mapas facilita a leitura de fenômenos sociais e culturais, oferecendo uma nova perspectiva para relacionar eventos desconexos a priori (MORETTI, 2008).

Uma tentativa recente de mapear espaços da Literatura Brasileira foi empreendida pelo Instituto Brasileiro de Geografia e Estatística- IBGE - (2009) no Atlas das Representaçóes Literárias de Regióes Brasileiras. O Brasil, neste caso, foi apresentado não pelas suas divisóes político-administrativas, mas em regióes em que os elementos culturais foram parâmetros fundamentais de sua constituição.

Com o ensejo de produzir um retrospecto histórico, sociológico e cultural da formação da culinária brasileira, Dória $(2009 ;$ 2014), concordando com a ideia lançada primordialmente pelo IBGE, mostrou que não é possível empreender um estudo da cultura da alimentação por meio das divisões regionais político- 
administrativas, e propôs, assim, a ideia de manchas culinárias, que são porçôes do território que constituem regióes para o estudo da alimentação.

A partir dessas bases é que a pesquisa intitulada Atlas Culinário da Literatura Brasileira: Alimentação e Cultura foi proposta em 2014. A pesquisa foi desenvolvida entre os anos de 2014 e 2018, organizada em duas fases: (1) mapeamento das obras de interesse e (2) síntese visando a responder às perguntas enunciadas na pesquisa. A primeira fase consistia num mapeamento das obras literárias, visando a um reconhecimento do campo, no sentido do estabelecimento do corpus da pesquisa e sua disposição nas manchas culinárias. As obras de arte são produtos da cultura capazes de representar os diversos reagrupamentos humanos, sendo através delas possível observar o comportamento individual e coletivo dos membros pertencentes a uma dada sociedade. Certa vez, disse Lévi-Strauss, que se a nossa espécie viesse a sucumbir por causa de uma hecatombe terrestre, e se restassem apenas as obras de arte, essas ofereceriam uma justa imagem do melhor que construímos como humanos (LÉVI-STRAUSS; ERIBON, 2005). Tal pensamento é pertinente, uma vez que cada grupo social em particular expressa suas emoçôes, sentimentos, vivências e características em suas representaçóes artísticas.

As obras foram mapeadas a partir de quatro níveis de exploração - busca difusa, busca acadêmica, busca no acervo da Biblioteca Nacional e brainstorming - durante o ano de 2014. Faziam parte da pesquisa oito alunos(as) e uma professora do curso de graduação em Nutrição, um professor de Ciências Sociais, um de Filosofia, duas professoras de Estudos da Linguagem, um geógrafo. O primeiro nível se revestia de um caráter livre e difuso. Foram consultados livros didáticos e obras de literatura. Em seguida, passou-se à busca no Google $e^{\oplus}$, utilizando alguns descritores obtidos com base nessas leituras, tais como: "autores regionalistas", "obras de 30", "literatura amazonense", "literatura caipira”, "literatura praieira”, dentre outros. Os resultados foram sendo consultados sempre em busca das referências relativas à alimentação.

Na sequência, procedeu-se à busca de trabalhos acadêmicos, produzidos em âmbito nacional, que pudessem fornecer pistas sobre obras que trazem a questão da alimentação em seus registros. Foram consultadas três bases de dados: o Jstor com os descritores "food", "culture", "literature", "Brazil"; Google Acadêmico e o Banco de Teses da Capes, com os descritores: "literatura", "alimentação" e "cultura". Em seguida, utilizando os mesmos descritores, foi realizada uma pesquisa no acervo da Biblioteca Nacional. 
Por último, nas sessões de estudos do Gula, os mediadores eram convidados a apresentar os resultados de sua busca individual. O grupo adicionava suas contribuições como em um brainstorming, uma técnica que visa a explorar ideias e pensamentos de um grupo designando um objetivo comum.

A partir disso, os autores chegaram a 50 obras da literatura brasileira que davam relevo à questão da alimentação, em diferentes porçôes do território nacional. Observou-se que a mancha meridional representava uma longa faixa do território com expressóes intensamente heterogêneas tanto do ponto de vista culinário quanto geográfico. Por esta razão, para melhor expressar o componente cultural, a mancha foi divida em três porçôes: a Meridional, os Sertôes e Central. Com isso, foi proposto um atlas com sete manchas culinárias, a saber: Amazônica, Caipira, Central, Costa, Meridional, Recôncavo Baiano e Sertóes, como pode ser visto a seguir na imagem 1 (CHAVES et al., 2016).

\section{Imagem 1. As sete manchas culinárias brasileiras}

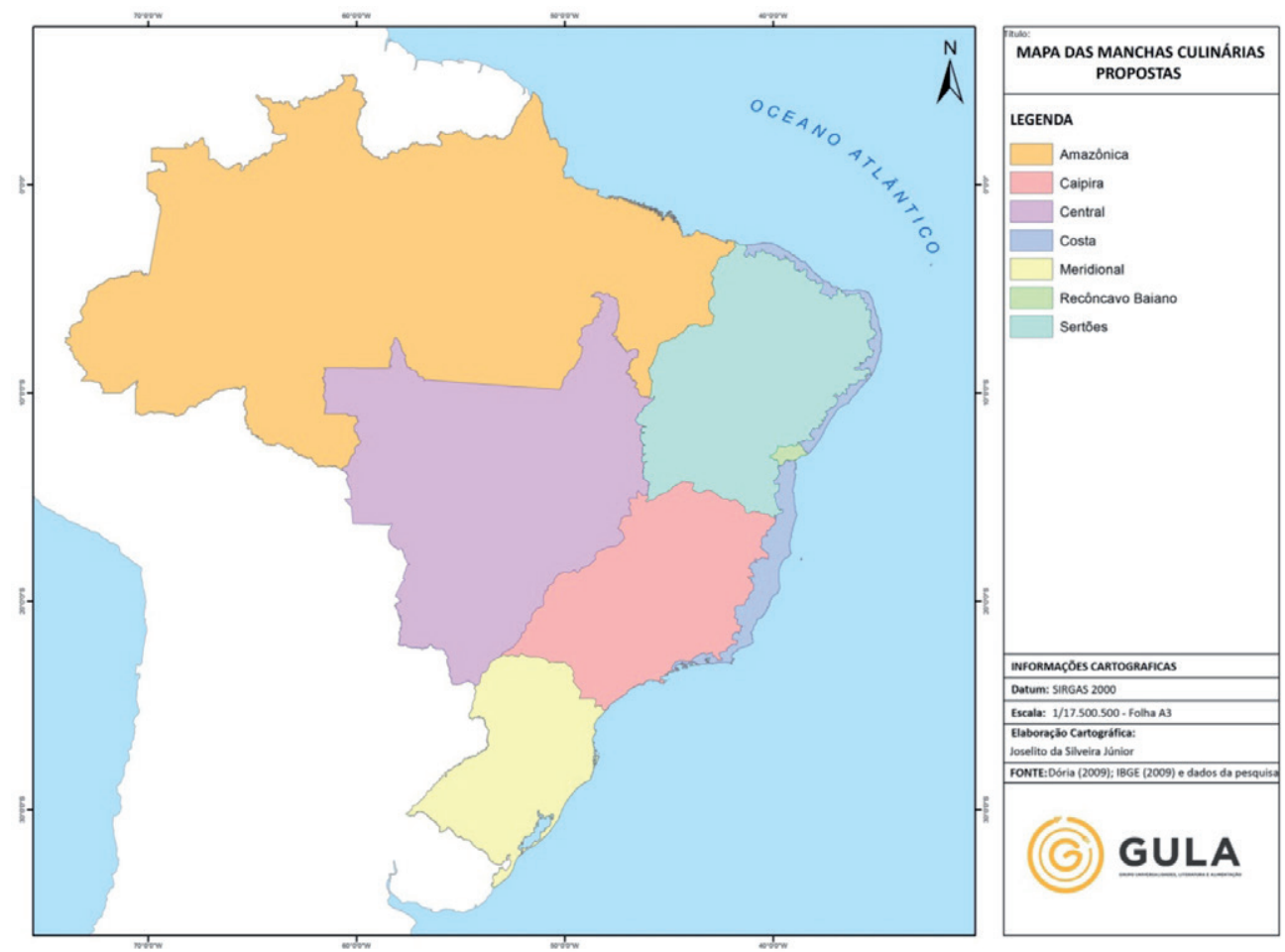

Fonte: (CHAVES et al., 2016). 
$\mathrm{Na}$ segunda fase, visando a um olhar crítico sobre a construção social do espaço alimentar, parte-se da ideia de espaço proposta por Santos (2006), que é compreendido como as relaçôes de sistemas de objetos e ações indissociáveis, cuja dialética sociedade e espaço trabalham em interação, e não isoladamente. Esperase, portanto, através do Atlas Culinário, estabelecer materialmente relações entre a construção do território brasileiro e as falhas no seu sistema alimentar, compreendidas como violações à garantia do direito humano à alimentação adequada no contexto da SAN, a partir de obras da literatura brasileira.

\section{Tipo de estudo e corpus selecionado}

A pesquisa é qualitativa do tipo explicativa, pois pretende relacionar a origem de falhas no sistema alimentar em análise com fenômenos sociais e históricos no espaço em análise.

Tomando como ponto de partida inicial as 50 obras mapeadas, foi aplicado o seguinte critério de exclusão: excluíram-se as obras que não faziam referências diretas ao contexto de sua produção, uma das dimensôes do espaço narrativo proposto por Hones (2017), restando um total de 27 a serem analisadas, conforme sistematização do quadro 1.

\section{Quadro 1. Corpus selecionado}

\begin{tabular}{|c|l|}
\hline Manchas & \multicolumn{1}{c|}{ Obras } \\
\hline Amazônica & $\begin{array}{l}\text { Poeta de água doce, Eliakin Rufino; Romanceiro, Elson Farias; Sol de feira, } \\
\text { Luiz Bacellar }\end{array}$ \\
\hline Caipira & $\begin{array}{l}\text { Quarto de despejo, Carolina Maria de Jesus; Poesia reunida, Adélia Prado; } \\
\text { Misereres, Adélia Prado; Bagagem, Adélia Prado; Vermelho Amargo, } \\
\text { Bartolomeu Campos de Queirós; Indez, Bartolomeu Campos de Queirós }\end{array}$ \\
\hline Central & $\begin{array}{l}\text { Tesouro da casa velha, Cora Coralina; Poema dos Becos de Goiás e Estórias } \\
\text { Mais, Cora Coralina; Vinde a mim as palavrinhas, Nicolas Behr }\end{array}$ \\
\hline Costa & $\begin{array}{l}\text { Homens e caranguejos, Josué de Castro; Uma aprendizagem ou o livro dos } \\
\text { prazeres, Clarice Lispector; Menino de engenho, José Lins do Rêgo }\end{array}$ \\
\hline Meridional & $\begin{array}{l}\text { O continente, Érico Veríssimo; A mesa voadora, Luis Fernando Veríssimo; Por } \\
\text { que sou gorda mamáe, Cíntia Moscovich }\end{array}$ \\
\hline
\end{tabular}




\begin{tabular}{|c|l|}
\hline Manchas & \multicolumn{1}{|c|}{ Obras } \\
\hline Recôncavo & $\begin{array}{l}\text { Dona flor e seus dois maridos, Jorge Amado; Gabriela cravo e canela, Jorge } \\
\text { Amado; Cacau, Jorge Amado }\end{array}$ \\
\hline Sertóes & $\begin{array}{l}\text { Vidas Secas, Graciliano Ramos; A bagaceira, José Américo de Almeida; } O \\
\text { Auto da Compadecida, Ariano Suassuna; O quinze, Rachel de Queiroz; } \\
\text { Não me deixes: suas histórias e sua cozinha, Rachel de Queiroz; Morte e vida } \\
\text { severina, Joáo Cabral de Melo Neto }\end{array}$ \\
\hline
\end{tabular}

Fonte: dados da pesquisa.

\section{Desenho do estudo e proposta analítica}

$\mathrm{Na}$ fase de síntese da pesquisa, com base no corpus e levantamento bibliográfico realizado pelo grupo, foi elaborado modelo conceitual para o espaço alimentar literário, com o objetivo de facilitar o processo de análise das obras, promovendo uma leitura orientada aos objetos. Dois membros da equipe, que participaram desde o princípio da pesquisa, com apoio de um geógrafo, foram diretamente responsáveis pela elaboração e teste do instrumento. Sua versão final encontra-se no quadro 2.

O modelo contém duas dimensóes: uma define o espaço narrativo, com três chaves de leitura tomadas a partir do modelo de Hones (2017) e a outra define objetos culinários, a partir de cinco (BRASIL, 2014; DÓRIA, 2014). O conjunto dos objetos culinários encontrados relacionados com elementos do espaço narrativo oferece uma leitura sobre o espaço alimentar literário, conformando assim, uma geoculinária brasileira.

Quadro 2. Modelo conceitual para análise com variáveis propostas

\begin{tabular}{|c|c|c|c|}
\hline \multirow{3}{*}{$\begin{array}{l}\text { Espaço } \\
\text { alimentar } \\
\text { literário ou } \\
\text { geoculinária } \\
\text { literária } \\
\text { brasileira }\end{array}$} & Dimensóes & Chaves de leitura & Referências \\
\hline & $\begin{array}{c}\text { Espaço } \\
\text { narrativo }\end{array}$ & $\begin{array}{l}\text { 1. Contexto de produção } \\
\text { 2. Voz ficcional } \\
\text { 3. Sentidos do leitor }\end{array}$ & (HONES, 2017) \\
\hline & $\begin{array}{l}\text { Objetos } \\
\text { culinários }\end{array}$ & $\begin{array}{l}\text { 4. Ingredientes in natura } \\
\text { 5. Ingredientes minimamente } \\
\text { processados e fraçóes } \\
\text { 6. Ingredientes industrializados } \\
\text { 7. Alimentos processados artesanalmente } \\
\text { e outras preparaçóes culinárias } \\
\text { 8. Bebidas }\end{array}$ & $\begin{array}{l}\text { (BRASIL, 2014; } \\
\text { DÓRIA, 2014) }\end{array}$ \\
\hline
\end{tabular}

Fonte: dados da pesquisa. 
$\mathrm{Na}$ fase de síntese, a partir de 2016, a equipe foi constituída de dez alunos(as) e três professoras da graduação em Nutrição, um aluno de graduação em Letras e quatro alunos de pós-graduação das Ciências Sociais (mestrado e doutorado).

Para sintetizar os elementos visando à elucidação de falhas de SAN, aplicou-se a abordagem de framework, que consiste em etapas que permitem ao pesquisador analisar os dados até que u ma relação coerente seja estabelecida entre eles (RITCHIE; SPENCER, 2002). As etapas consistem em:

(1) familiarização com os dados, com o fim de estabelecer uma codificação temática do material usando as chaves de leitura do quadro 2 como suporte (subdimensôes);

(2) descrição, que envolve uma síntese das informações em relação aos temas elucidados em um exercício crescente de codificação dedutiva (subtemas) e;

(3) interpretação, onde os dados seráo reduzidos para apresentar resultados em um nível razoável de abstraçáo. Por meio do agrupamento de dados, o número de categorias será reduzido colapsando as que estiverem relacionadas em categorias mais amplas (temas principais ou falhas).

Um exemplo de aplicação dessa metodologia de análise pode ser visto na Imagem 2.

\section{Imagem 2. Um exemplo do processo de abstração na análise de framework}

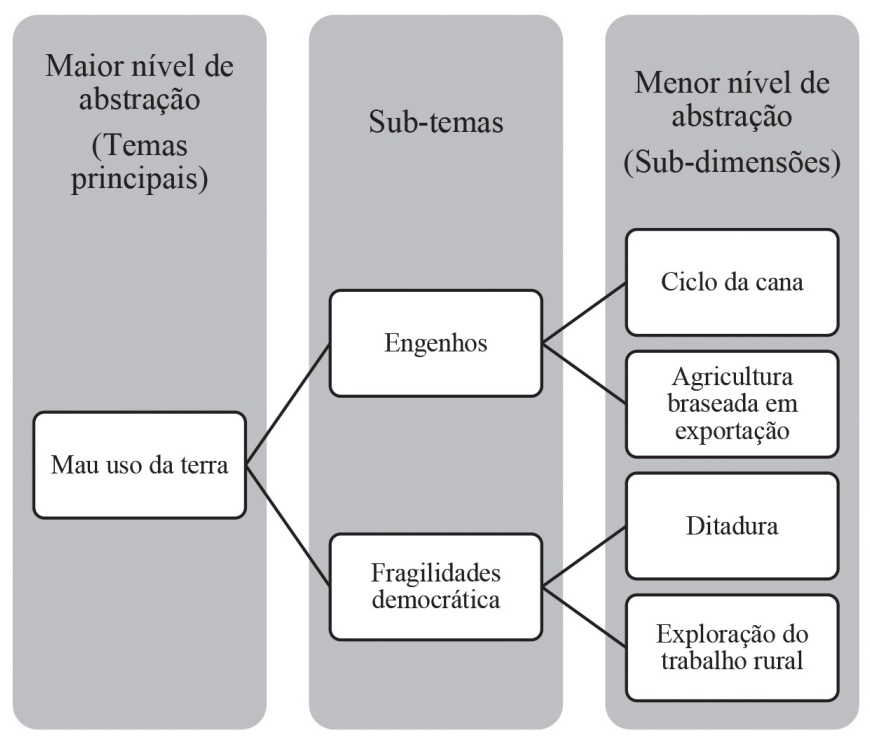

Fonte: elaborado pelos pesquisadores. 


\section{Resultados e Discussão}

\section{Caracterização das obras}

No que tange ao espaço narrativo, tem-se que as obras, em seu contexto de produção, encontram-se em um intervalo temporal de 86 anos (a partir da década de 20) e ficcional de, pelo menos, 270 anos a partir dos eventos históricos citados, tal como a formação do Estado do Rio Grande do Sul ( $O$ continente, Erico Verissimo).

Os autores da mancha Amazônica estáo inseridos em movimentos de base modernista, visando à valorização da expressão cultural amazônica, tais como Roraimeira e Clube da Madrugada. São contemporâneos de um dos períodos de crise do Ciclo da Borracha e das consequentes transformaçóes econômicas no território. $\mathrm{O}$ espaço ficcional deu relevo aos rios, flora e fauna locais e à ligação do homem com a natureza, estabelecendo uma ecologia: homem como parte do ambiente. Luiz Bacellar, com seus rondéis e as frutas nativas, em Sol de Feira, foi um dos autores que mais tentaram operar a ideia da antropofagia: nem assimilação de um ideal estético e cultural colonizador, burguês; tampouco a estabilização de uma cultura, sob a ideia da definição da identidade local. A adoção de um regime antropofágico opóe-se àquele que defende o regional que não se proponha universal (ANDRADE, 1928). Valorização da biodiversidade e de saberes de comunidades tradicionais foram temas de destaque neste espaço narrativo (Romanceiro, Elson Farias). Acerca dos objetos culinários encontrados, observou-se uma ampla variedade de produtos in natura como frutas (buriti, pitanga, limão, manga, banana), espécies de peixes de água doce, como o pirarucu, e mel (Poeta de água doce, Eliakin Rufino). A farinha, principalmente a de mandioca, ocupou destaque entre os componentes minimamente processados, sendo um alimento básico utilizado puro ou em preparaçóes, tais como pirôes e farofas.

As obras da mancha Caipira são marcadas por temas familiares (obras de Bartolomeu Campos de Queirós), rurais (obras de Adélia Prado) e periféricos (Quarto de despejo, Carolina Maria de Jesus) que, entretanto, não deixam de refletir sobre as conjunturas da época no país: discursos de emancipação feminina e fortalecimento das desigualdades sociais no cenário da ditadura. Os escritos guardam um componente de indagaçáo sobre a condição humana: a dor, a saudade, a religiosidade, a felicidade, e a comida sempre aparecem como veículo destes afetos. A valorização de ingredientes locais e do ato de cozinhar, o componente 
afetivo ligado à alimentação, com destaque para Indez, de Bartolomeu Campos, e a crítica social ligada à fome são temas de interesse nesta mancha. Seus objetos culinários foram caracterizados pela presença de produtos de origem animal como leite, ovos e carne, variedade de alimentos industrializados, ricos em gordura, além de vegetais e produtos de horta.

$\mathrm{Na}$ mancha Central, tem-se uma literatura produzida em um momento nacional de protesto e resistência ao período da ditadura militar. Isso fica mais evidente na obra que tem como referência o contexto urbano de Brasília (Vinde a mim as palavrinhas, Nicolas Behr). Os cenários ficcionais são diversos: do campo à cidade. Em ambos, o homem, com sacrifício, vive do fruto de seu trabalho, tal como a doceira poetisa Cora Coralina. Todavia, na cidade, o fosso das desigualdades sociais torna-se mais evidente: o descaso com os humildes trabalhadores que passaram suas vidas para construir a cidade e não têm onde morar, a alimentação que é escassa. São vários elementos que convergem em uma crítica à migraçáo para os grandes centros urbanos e a um reforço positivo do desenvolvimento rural. Em relação aos objetos culinários, a mancha apresentou pouca variedade e presença marcante de produtos industrializados como refrigerante e carnes processadas.

As obras da mancha da Costa trazem o cenário efervescente do Brasil das décadas de 30 a 60 , que são vividas exponencialmente nesta mancha, principalmente devido aos grandes latifúndios dos engenhos, monoculturas e usinas, que ali se localizavam. Dentre seus personagens há aqueles que migraram forçadamente pela fome e passaram a habitar os mangues (Homens e caranguejos, Josué de Castro), os que migraram em busca de si, como Lori, que saiu do interior do Rio de Janeiro e mudou-se para a capital (Uma aprendizagem, Clarice Lispector), e aqueles que se deslocaram em função de tragédias familiares, como Carlinhos em Menino de engenho (José Lins do Rego). Comida como necessidade, tendo a fome como produto de injustiças sociais, e seu outro extremo, a comida como fonte de prazer e de experimentação, são temas que trouxeram no seio do espaço grandes distinçôes de classe construídas pelas injustiças sociais. Compreende uma multiplicidade de objetos culinários, sendo marcante a presença de carne bovina, aves (galinha, galo e peru) e frutas como cajá, maçâ, figo, goiaba e coco. Tratando-se de um espaço de manguezais, o consumo de caranguejo se estende pela costa do Brasil. Além disso, uma das principais características da mancha são os produtos oriundos da cana-deaçúcar como açúcar, rapadura, melaço e, principalmente, a cachaça. 
As obras da mancha Meridional privilegiam as referências ao extremo sul do Brasil e aos intensos fluxos culturais que perpassam esse local: seja durante o processo de formação do estado, em $O$ Continente (Erico Verissimo), seja pelo trânsito de imigrantes europeus, evidenciados por Cíntia Moscovich (Por que sou gorda, mamãe?), ou pelo turismo gastronômico, notadamente europeu, de Luis Fernando Verissimo ( $A$ mesa voadora). O trânsito espacial é intenso e a dimensão temporal, ampla. Temas como a formação da culinária brasileira e dilemas do comensal contemporâneo produzidos pelos excessos são de interesse neste espaço. É notável a difusão de produtos industrializados a partir de carnes processadas, como também alto consumo de produtos açucarados. $\mathrm{O}$ vinho, o chimarrão e a cachaça são as principais bebidas encontradas nessa mancha, acompanhando preparaçóes culinárias influentes na região: churrasco e queijo.

A mancha do Recôncavo é marcada pelo Ciclo do Cacau, grandes oligarquias rurais e sua transição para o acelerado desenvolvimento urbano-industrial. Jorge Amado denunciou as duras condiçôes de vida dos trabalhadores rurais da zona cacaueira do sul da Bahia, expondo o Brasil das oligarquias. Temas como as injustiças sociais na produção de alimentos, cozinhar como ritual sagrado, em Dona Flor, e as relaçôes entre gênero feminino e cozinha são temas pertinentes neste espaço. Sobre a questão feminina, por exemplo, apresentam-se em todas as obras estruturas patriarcais dominantes, onde o universo é naturalizado como espaço das mulheres. Em relação aos objetos culinários, na "cozinha de santos" destacaram-se alguns elementos culinários como óleo de dendê, cachaça, farinha de mandioca e doces.

As mazelas políticas, sociais e históricas, relatadas nos romances com alto teor de crítica social, são a marca da mancha dos Sertôes. A fome como produto de injustiças sociais é recorrente nas obras regionalistas. Ela vem acompanhada de temas como: seca e movimentos migratórios (Vidas Secas, Graciliano Ramos; O quinze, Raquel de Queiroz; Morte e Vida Severina, João Cabral de Melo Neto), coronelismo e exploração do trabalho ( $A$ bagaceira, José Américo de Almeida), fanatismo religioso e cangaço ( $O$ auto da compadecida, Ariano Suassuna), as oscilaçóes entre fartura e penúria ( $O$ não me deixes, Raquel de Queiroz), que trazem elementos do contexto de produção das obras e do espaço ficcional criado pelos autores. Marcada pelas injustiças sociais e pelo fantasma da fome, essa regiáo tem traços culinários bem característicos desses eventos. A farinha, o sal, a rapadura e a tripa compóem a alimentação do território, além de produtos como milho e feijão. 
Para fins de uma leitura da geoculinária literária brasileira, percebeu-se que as obras trazem uma reflexão sobre as conjunturas do país: como os ciclos econômicos de monoculturas, regimes políticos autoritários, processo de industrialização tardio, dentre outros. Conforme pode ser observado na imagem 3.

\section{Imagem 3. Falhas do sistema alimentar}

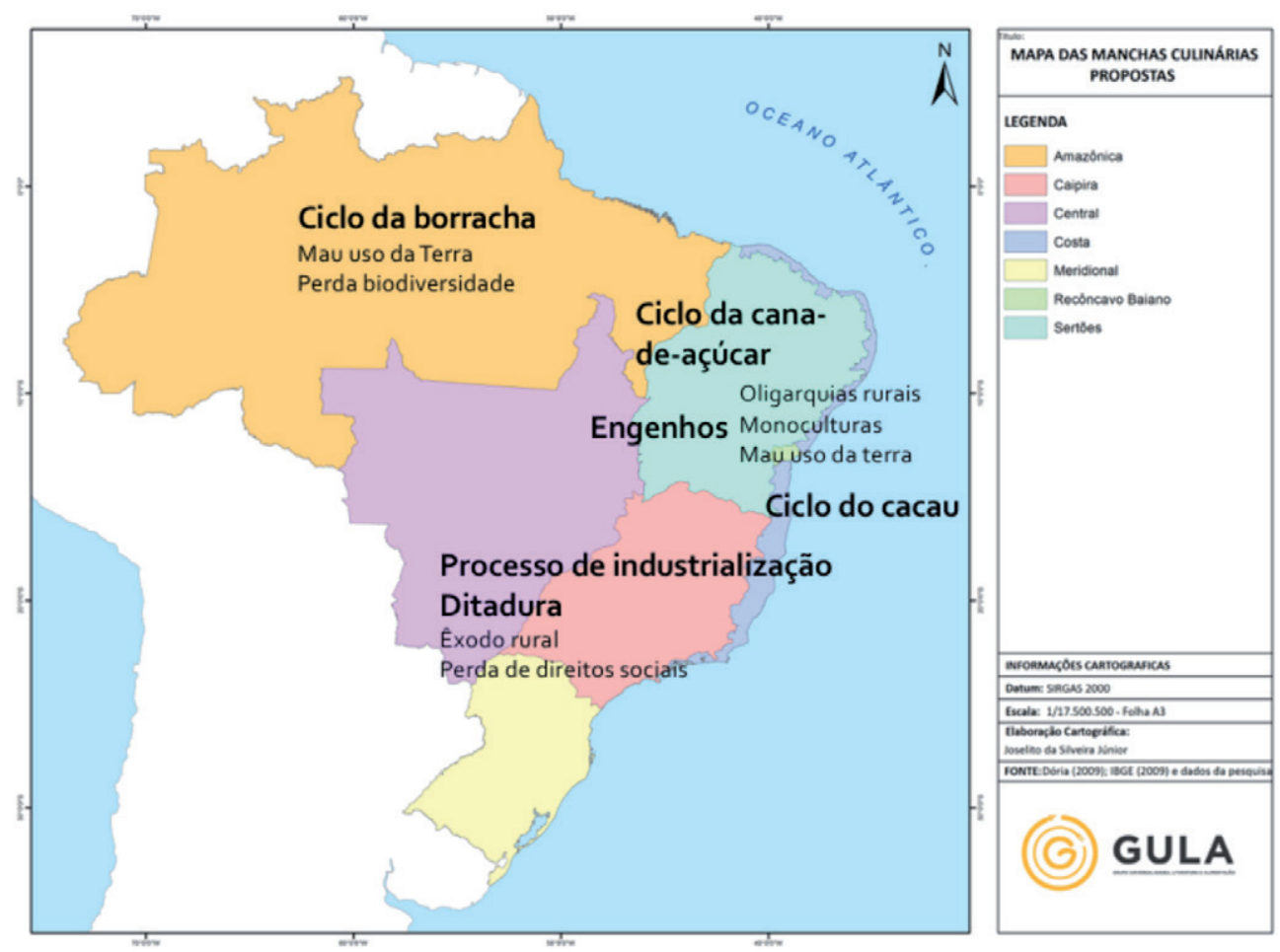

Fonte: dados da pesquisa.

A fome como produto de injustiças sociais atravessa todo o espaço e o tempo narrativo e traz consigo diversas questóes sociais ainda em pauta hoje no país: uso da terra, exploração do trabalho, corrupção, apropriação de recursos naturais. As estruturas patriarcais são dominantes: no ambiente doméstico, ao naturalizar a culinária como espaço das mulheres; na vida pública, ao perpetuar as injustiças por geraçôes por meio dos latifúndios e de suas monoculturas. Discussóes ainda atuais em uma análise ampla do sistema alimentar brasileiro pela ótica da SAN. A seguir, há algumas destas falhas explicitadas com exemplos das obras e em discussão com o contexto histórico brasileiro. 


\section{Falhas da segurança alimentar e nutricional}

Segundo Rocha (2013), a insegurança alimentar e nutricional fundamenta-se na ideia de falha de mercado, gerada pela presença de externalidades que influenciam o sistema, tais como relaçôes de poder desiguais, ônus social desconsiderado no preço de mercadorias alimentares e incapacidade de mercados livres gerarem bens públicos de forma satisfatória.

$\mathrm{Na}$ análise da geoculinária brasileira, uma das falhas geradas por essas externalidades pode ser apontada como o mau uso da terra. O uso da terra é caracterizado pelos arranjos, atividades e insumos que as pessoas desenvolvem em um determinado tipo de cobertura (FAO, 2012). Segundo a Lei 4504/1964, que dispóe o Estatuto da Terra, o uso da mesma deve estar intrinsecamente vinculado a uma função social condicionada ao bem-estar coletivo.

No texto ficcional analisado, pode ser citado o exemplo de Severino, protagonista da obra Morte e vida severina, um migrante sertanejo que saiu em busca de uma vida mais digna na capital pernambucana. A obra narra a caminhada de Severino do sertão até Recife. A morte o rodeia por todos os lados. Em uma das cenas, Severino assiste a um enterro de um trabalhador rural e escuta o que os amigos do morto dizem no cemitério:

- Essa cova em que estás, com palmos medida, é a conta menor que tiraste em vida.

- É de bom tamanho, nem largo nem fundo, é a parte que te cabe deste latifúndio.

- Não é cova grande, é cova medida, é a terra que querias ver dividida. 


\section{- É uma cova grande \\ para teu pouco defunto, mas estarás mais ancho \\ que estavas no mundo. \\ - É uma cova grande \\ para teu defunto parco, porém mais que no mundo \\ te sentirás largo. \\ - É uma cova grande \\ para tua carne pouca, mas a terra dada não se abre a boca.}

João Cabral faz uma denúncia social do Brasil de sua época e de tantas vidas severinas que ali foram ceifadas pelo mau uso da terra. O Brasil está entre os países com maior grau de concentração de terra no mundo: menos de 1\% dos proprietários agrícolas possui $45 \%$ da área rural do país (OXFAM AMÉRICA, 2016). Esse processo de criação de latifúndios inicia-se com a colonização através das chamadas sesmarias, na sequência, em 1850, com a chamada Lei das Terras, e se intensifica no século XX com o processo de modernização da agricultura brasileira (ALENTEJANO, 2012).

Além do problema gerado pela concentração em si, destaca-se o mau uso da terra pela pecuária bovina extensiva no Brasil. De Sy et al. (2015), em um estudo sobre o uso da terra em países da América Latina, demonstraram que, entre 1990 e 2005, mais de $80 \%$ da terra desmatada no país são atribuídos à pecuária, figurando assim como a principal contribuição brasileira para o aquecimento global.

O mau uso da terra é uma das consequências do processo de modernização da agricultura brasileira, que vem alavancando uma segunda falha característica do sistema agroalimentar brasileiro o processo de comoditização da comida. A privação quantitativa e qualitativa no acesso a alimentos é uma constante no cenário da geoculinária brasileira. A tônica da produção de alimentos é marcada por commodities que ditam o que, quando produzir e para quem. Os ciclos das monoculturas - canade-açúcar, cacau, café - orientadas para produção em série de uma certa commodity 
são bons exemplos trazidos pelas obras. A obra Cacau, de Jorge Amado, por exemplo, é a história de Cordeiro, um trabalhador de roça de cacau sergipano, da infância à vida adulta, narrada em primeira pessoa. Cordeiro trabalha na Fazenda Fraternidade, cujo proprietário é o coronel Mané Frajelo. A maior parte da trama se passa zona cacaueira do Pirangi, município de Ilhéus, Bahia. O ambiente é de chuvas constantes e abastança de alimentos para as famílias de posses e de regime de semiescravidão e miséria para os trabalhadores. Jorge Amado em sua obra denunciou as duras condições de vida dos trabalhadores rurais da zona cacaueira do sul da Bahia. O Brasil das commodities de Jorge Amado mostra o que é morrer de sede em frente ao mar.

O Brasil é um país mundialmente importante na produção agrícola e diversidade de alimentos. Todavia, aspectos do sistema alimentar produtivo, tais como a estrutura fundiária concentrada e o equilíbrio entre a produção de commodities direcionada para o mercado internacional e de alimentos para o consumo têm reflexos significativos sobre o estado de insegurança alimentar e nutricional de sua população, tais como falhas no acesso da população local a alimentos e crescimento paralelo do uso de agroquímicos e dos alimentos geneticamente modificados, sob a justificativa de produção insuficiente de alimentos para todos (FAO, 2014b; 2015; CONSEA, 2014).

A garantia do direito humano à alimentação adequada - prevista no artigo 6 da Constituição Federal, em um cenário de comoditização da comida, ou seja, onde o alimento é mercadoria, submetido às flutuaçôes dos mercados financeiros privados - é um dos grandes desafios impostos ao sistema alimentar brasileiro. Desafio ainda maior em um cenário onde o Estado não desempenha mais um papel de regulador, um árbitro, em benefício dos equilíbrios territoriais e sociais, entre os interesses do capital privado e dos bens públicos. Milton Santos (1997) caracterizou esse papel como de facilitador, devido à primazia do econômico sobre o político, do instrumental sobre a finalidade e do dinheiro sobre o homem. O resultado é a contração empresarial dos recursos ligados à produção de alimentos - água, sementes, terra - bem como dos meios de produção fabris e dos meios de comercializacão em rede dos alimentos processados (VIVAS, 2017).

O Brasil, talvez em um cenário mais preocupante que o trazido à tona por Milton Santos, vem enfrentando sérias ameaças à garantia do direito humano à alimentação adequada, relacionadas a problemas de má governança. Sabe-se que as maiores ameaças à boa governança procedem da corrupção, da violência e da pobreza, que prejudicam a transparência, a segurança, a participação da população e seus 
direitos fundamentais (KI-MOON, 2009). Na legislatura 2015-2018, por exemplo, a bancada ruralista brasileira possui 222 parlamentares, sendo 201 deputados e 11 senadores, correspondendo a 39\% da Câmara e a 13\% do Senado, o que garante a aprovação de projetos e leis que atendam aos interesses dos agentes hegemônicos do agronegócio brasileiro (LOCATEL; LIMA, 2016).

Some-se a esse contexto a regulação insuficiente da indústria de alimentos, que resulta na oferta indiscriminada de alimentos industrializados prontos para consumo (MONTEIRO, et al., 2015). Há um vasto escopo de evidências científicas que relaciona o consumo de alimentos ultraprocessados e o desenvolvimento de doenças crônicas não transmissíveis. Ainda assim, sua oferta é indiscriminada, sobretudo nos países em desenvolvimento (WHO, 2016).

No Brasil da década de 30, o presidente Getúlio Vargas lançou as bases do projeto nacional de industrialização no país. A commodity do café desempenhou um papel notório na canalização dos recursos do setor agrário-rural para o urbanoindustrial (DEL FIORI; MONTEIRO, 2011). O século XX, assim, assistiu a um rápido processo de intensificação de exportação de produtos primários processados e abertura ao capital estrangeiro. Hoje, a produção e o estímulo ao consumo de produtos processados industrialmente constituem-se como uma importante falha do sistema alimentar brasileiro (SCRINIS; MONTEIRO, 2017).

A substituição de alimentos in natura, minimamente processados, e preparações culinárias à base de vegetais por produtos industrializados prontos para consumo é uma das tônicas verificadas no estudo da geoculinária brasileira. Obras da mancha Central, por exemplo, demonstram isso. Vinde a Mim as Palavrinhas, de Nicolas Behr, é composto por 125 poemas que fazem crítica social ao plano piloto e à construção da cidade de Brasília. $\mathrm{O}$ autor, que fala na voz de construtores, população e parlamentares da cidade de Brasília, retrata o descaso com os humildes trabalhadores que migraram do campo para construir a cidade e que sequer conseguem comer adequadamente. Carnes processadas, refrigerantes e outros produtos processados industrialmente passam a figurar em sua alimentação. Em Mesa Voadora, Luis Fernando Verissimo critica com veemência os efeitos da indústria alimentar sobre os sujeitos e expande-se à discussão para a publicidade de alimentos. No capítulo intitulado "O Ovo" há uma reflexão sobre o fenômeno que Fischler chama de gastro-anomia: incertezas ligadas ao campo da alimentação, fruto da proliferação de discursos sobre o tema alimentar (FISCHLER; MASSON, 2010). 
Sistemas alimentares tradicionais e os padrôes alimentares estabelecidos há muito estão sendo remodelados rapidamente, sobretudo nos países com as fragilidades típicas do passado colonial, por produtos ultraprocessados produzidos por corporaçóes alimentares transnacionais, as chamadas Big Food (MONTEIRO; CANNON, 2012). Como resultado, nos últimos dez anos a obesidade cresceu mais de $60 \%$ no país. Os mais afetados são aqueles com menor escolaridade e renda (BRASIL, 2016).

As três falhas listadas - mau uso da terra, comoditização da comida e oferta indiscriminada de alimentos industrializados - são elementos interligados e indicadores de um sistema alimentar em crise. Sua reforma requer uma abordagem ampla, compreensão holística de seu funcionamento e governança participatória, o que certamente é um dos passos essenciais na construção da democracia alimentar (IPES, 2015; 2017).

\section{Considerações finais}

Diante dos resultados desta pesquisa, percebe-se o papel de protagonismo político que a Nutrição implicada com a abordagem de sistemas alimentares pode conquistar no cenário atual, onde o presente e o passado conectam-se para fragilizar a SAN no território brasileiro. Destacou-se o papel das Ciências Humanas e Sociais na análise de problemas do sistema alimentar relacionados com aspectos socioculturais.

A palavra política, mais do que nunca, reveste-se de um caráter controverso no cenário brasileiro. Por um lado, tem-se um Estado que abandona as necessidades da sociedade em nome dos interesses dos atores hegemônicos globais, sob a égide de um governo que ameaça a democracia, os direitos humanos e as políticas sociais. Por outro, compreende-se que a política se encontra para além da ordem partidária estabelecida, ela é a essência da condição humana. É apenas por meio de atos políticos, da ação ativa no mundo, que se pode transformar ideias em ações em busca da SAN.

Mais do que orientaçóes sobre o que comer, a Nutrição que vise ao fortalecimento da democracia alimentar no âmbito da Saúde Coletiva deve problematizar o porquê de comer o que comer e, assim, construir subsídios para a transformação de um sistema alimentar em que os cidadáos sejam atuantes por meio de sua presença ativa em instâncias de participação social, em que os profissionais sejam formados para atuar na elaboração de uma agenda futura que comporte as complexidades da Nutrição a serem abordadas em políticas, pesquisas, extensão ou ainda a prestação 
de serviços relevantes para a comunidade, visando ao fortalecimento da SAN. E, por fim, onde as pesquisas científicas sejam alinhadas com a perspectiva da alimentação adequada e saudável enquanto direito humano.

A possibilidade de uma abordagem transdisciplinar, própria do texto literário, bem como a leitura facilitada de fenômenos sociais e culturais por meio de mapas, fazem da geografia literária uma importante ferramenta de apoio ao fortalecimento da democracia alimentar, oferecendo uma leitura sistêmica e problematizadora das relaçôes que a Nutrição estabelece com as questôes mais amplas ligadas à dimensão social da alimentaçáo, apoiando assim o processo de fortalecimento da SAN com soberania e cidadania alimentar no país.

Nesta pesquisa, o grupo lidou com uma grande densidade de dados em uma perspectiva de análise qualitativa. O presente artigo cumpriu seu papel em oferecer um panorama das principais questóes emergentes neste corpus a partir das questôes enunciadas. Trabalho futuros poderão explorar com mais detalhes a riqueza de dados produzidos no decorrer desta pesquisa e, ainda, poderão apontar perspectivas procedimentais de utilização da geografia literária em açôes de EAN, sobretudo no âmbito do Programa Nacional de Alimentação Escolar. ${ }^{1}$

\section{Agradecimentos}

Ao CNPq, pelo financiamento da pesquisa; aos membros do Grupo Universalidades, Literatura e Alimentação (Gula), no qual a ideia de construção do Atlas nasceu; e a todos os pesquisadores que colaboraram até aqui com o aprimoramento da pesquisa e diretamente com a coleta de dados.

\section{Referências}

ALENTEJANO, P. Limite da propriedade de terra no Brasil não acabaria com as grandes propriedades. Rio de Janeiro: EPSJV/Fiocruz, ago. 2012. Entrevista concedida a Raquel Júnia, entrevistador.

ANDRADE, O. Manifesto antropófago. Revista de Antropofagia, n. 1, 1928.

ASSOCIAÇÃO BRASILEIRA DE SAÚDE COLETIVA. Dossiê Abrasco: um alerta sobre os impactos dos agrotóxicos na saúde. Rio de Janeiro: Escola Politécnica de Saúde Joaquim Venâncio, 2015.

BARTHES, R. Aula. São Paulo: Cultrix, 2007. 
BRASIL. Lei n. 11.346, de 15 de setembro de 2006. Cria o Sistema Nacional de Segurança Alimentar e Nutricional - SISAN com vistas a assegurar o direito humano à alimentação adequada e dá outras providências. Brasília: CONSEA, 2006.

BRASIL. Marco de Referência de Educação Alimentar e Nutricional para as Políticas Públicas. Brasília: Ministério do Desenvolvimento Social, 2012.

BRASIL. Guia alimentar da população brasileira. Brasília: Ministério da Saúde, 2014.

BRASIL. Vigilância de fatores de risco e proteçâo para doenças crônicas por inquérito telefônico. Brasília: Ministério da Saúde, 2016.

CASTRO, J. Geografia da fome. O dilema brasileiro: pão ou aço. Rio de Janeiro: Civilização brasileira, 2006.

CHAVES, V. et al. Atlas culinário da literatura brasileira: alimentação e cultura. Revista Ciência Plural, v. 2, n. 3, p. 72-81, 2016.

CONSELHO NACIONAL DE SEGURANÇA ALIMENTAR E NUTRICIONAL. Análise dos indicadores de segurança alimentar e nutricional. Brasília: CONSEA, 2014.

DE SY, V. et al. Land use patterns and related carbon losses following deforestation in South America. Environmental Research Letters, v. 10, 2015.

DEL FIORI, D.; MONTEIRO, S. Industrialização do brasil na década de 1930: uma análise com teoria dos jogos. Análise, v. 22, n. 2, p. 101-114, 2011.

DÓRIA, C. A formação da culinária brasileira. São Paulo: Publifolha, 2009. . A formação da culinária brasileira. São Paulo: Três Estrelas, 2014.

FISCHLER, C.; MASSON, E. Comer: Alimentação de franceses, outros europeus e americanos. São Paulo: Ed. Senac SP, 2010.

FOOD AND AGRICULTURE ORGANIZATION OF THE UNITED NATIONS. FRA 2015 terms and definitions. Rome: FAO, 2012.

. Sustainable Diets and Biodiversity: Directions and Solutions for Policy, Research and Action. Rome: FAO, 2012.

. Sustainability assessment of food and agriculture systems (SAFA). Guidelines. Rome: FAO, 2014a.

. O estado da segurança alimentar e nutricional no Brasil: um retrato multidimensional. Brasília: FAO, 2014b.

. The State of Agricultural Commodity Markets 2015-16. Rome: FAO, 2015.

HIGH LEVEL TASK FORCE OF GLOBAL FOOD AND NUTRITION SECURITY. All food systems are sustainable. FAO, UNCTAD, UNIDO, World Bank, 2015. 
HONES, S. Literary geography. In: RICHARDSON, D. The encyclopedia of geography. New Jersey: John Wiley \& Sons, 2017.

INSTITUTO BRASILEIRO DE GEOGRAFIA E ESTATÍSTICA. Atlas das representaçôes literárias de regióes brasileiras. Rio de Janeiro: IBGE, 2009.

INTERNATIONAL PANEL OF EXPERTS ON SUSTAINABLE FOOD SYSTEMS. The new science of sustainable food systems. Overcoming barriers to systems reform. Belgium: IPES, 2015.

. Unravelling the Food-Health Nexus: Addressing practices, political economy, and power relations to build healthier food systems. Belgium: IPES, 2017.

KI-MOON, B. A ONU e a governança. ONUBR, São Paulo, 19 fev. 2009.

LANG, T. Food policy for the 21st century: can it be both radical and reasonable? In: KOC, M.; MACRAE, R.; MOUGEOT, L. For Hunger-Proof Cities: Sustainable Urban Food Systems. Ottawa: The International Development Research Centre, 1999.

LANG, T. Food control or food democracy? Re-engaging nutrition with society and the environment. Public Health Nutrition, v. 8, n.6, p. 730-737, 2005.

LAWRENCE, M. et al. Formulating policy activities to promote healthy and sustainable diets. Public Health Nutrition, v. 18, n. 13, p. 2333-2340, 2015.

LÉVI-STRAUSS, C; ERIBON, D. De perto e de longe. São Paulo: Cosac Naify, 2005.

LOCATEL, C; LIMA, F. Agronegócio e poder político: políticas agrícolas e o exercício do poder no Brasil. Sociedade e Território, v. 28, n. 2, p. 57-81, 2016.

MALUF, R. S; REIS, M.C. Segurança alimentar e nutricional na perspectiva sistêmica. In: ROCHA, C; BURLANDY, L.; MAGALHÃES, R. Segurança alimentar e nutricional: perspectivas, aprendizados e desafios para as políticas públicas. Rio de Janeiro: Fiocruz, p.43-67, 2013.

MASON, P.; LANG, T. Sustainable diets. How ecological Nutrition can transform consumption and the food system. New York: Routledge, 2017.

MONTEIRO, C.; CANNON, G. The impact of transnational "big food" companies on the South: a view from Brazil. Plos Medicine, v. 9, n. 7, 2012.

MONTEIRO, C. et al. Alimentos ultraprocessados e perfil nutricional da dieta no Brasil. Rev Saúde Pública, v. 48, n. 38, p. 1-11, 2015.

MORETTI, F. A literatura vista de longe. Porto Alegre: Arquipélago Editorial, 2008.

OXFAM AMÉRICA. Terra, poder e desigualdade na América Latina. Oxford: Oxfam, 2016.

PILNICK, A.; SWIFT, J. Qualitative research in nutrition and dietetics: assessing quality. Journal of Human Nutrition and Dietetics, v. 24, p. 209-214, 2010.

RAMOS, F.; SANTOS, L.; REIS, A. Educação alimentar e nutricional em escolares: uma revisão de literatura. Cad. Saúde Pública, v. 29, n. 11, p. 2147-2161, 2013. 
RITCHIE, J.; SPENCER, L. Qualitative data analysis for applied policy research. In: BRYMAN, A.; BURGESS, B. (Eds.). Analyzing Qualitative Data. London: Routledge, 2002.

ROCHA, C. A Contribuição da Economia para a análise de políticas públicas de segurança alimentar e nutricional. In: ROCHA, C.; BURLANDY, L.; MAGALHÃES, R. (Orgs.). Segurança Alimentar e Nutricional: perspectivas, aprendizados e desafios para as políticas públicas. Rio de Janeiro: Ed. Fiocruz, 2013.

SANTOS, M. A revanche do território. Folha de São Paulo, São Paulo, 3 ago 1997.

SANTOS, M. A natureza do espaço: técnica e tempo, razão e emoção. São Paulo: Editora da Universidade de São Paulo, 2006.

SANTOS, R. Mapa da alimentação da literatura brasileira: o território na promoção da alimentação adequada nas escolas. In JACOB, M. (Org.). Comer bem, viver bem: arte, cultura e educação. Natal: Aliá, 2016.

SCRINIS, G.; MONTEIRO, C. Ultra-processed foods and the limits of product reformulation. Public Health Nutrition, p. 1-6, 2017.

VIVAS, E. O negócio da comida: quem controla nossa alimentação? São Paulo: Expressão Popular, 2017.

WALK FREE FOUNDATION. The global slavery index 2016. Nedlands, Australia: Walk Free Foundation, 2016.

WORLD HEALTH ORGANIZATION. Fiscal Policies for Diet and Prevention of Noncommunicable Diseases. Geneva: WHO, 2016.

\section{Nota}

${ }^{1}$ M. C. M. Jacob e V. M. Chaves contribuíram igualmente para a concepçáo do projeto, análise e interpretação de dados, elaboração, revisão crítica de conteúdo intelectual e aprovação da versão final a ser publicada. 


\section{Abstract}

Failures on Brazilian food system:

contributions from literary geography to

enhance food democracy

The need to reformulate food systems is a constant in the debates of Food and Nutrition Policies worldwide. The science of Nutrition, in this scenario, has the opportunity to evaluate its hegemonic approach, linked to the biological paradigm, aiming at a greater political engagement in issues that weaken its food system. This work aimed to demonstrate how the historical and social process of construction of the Brazilian food system is related to current food and nutritional security deficiencies. This is qualitative research, which took as a method perspective the literary geography. The Brazilian territory was divided into seven culinary spots, portions of the territory that form regions for the social study of food. Their corpus consisted of 27 literary works, from 20 Brazilian writers, collected and analyzed with the support of the conceptual dimensions defined in the study: narrative spaces and culinary objects. The misuse of land, the commoditization of food and the indiscriminate supply of industrialized food were listed as the main flaws in the food system analyzed. The Humanities and Social Sciences approach can offer an important contribution to Nutrition in order to play a greater role in food system problems related to sociocultural aspects.

> Keywords: Food and Nutrition Security; sustainable development; Food and Nutrition Education; sociological factors; qualitative research. 